\title{
The effect of perinatal omega-3 fatty acid supplementation on inflammatory markers and allergic diseases: a systematic review*
}

\author{
CM Klemens, ${ }^{a}$ DR Berman, ${ }^{b}$ EL Mozurkewich ${ }^{\text {b }}$ \\ ${ }^{a}$ Michigan State University, East Lansing, MI ${ }^{b}$ Department of Obstetrics and Gynecology, Division of Maternal Fetal Medicine, University of \\ Michigan, Ann Arbor, MI, USA \\ Correspondence: Dr EL Mozurkewich, University of Michigan Medical Center, Division of Maternal Fetal Medicine, F4835, Box 0264 Mott \\ Hospital, 1500 E. Medical Center Drive, Ann Arbor, MI 48109-0264, USA. Email mozurk@med.umich.edu
}

Accepted 24 November 2010.

Background Maternal supplementation with omega-3 polyunsaturated fatty acids (n-3 PUFA) may modulate immune responses and allergy in neonates and children.

Objective To determine if $\mathrm{n}-3$ PUFA supplementation during pregnancy and lactation reduces risk for childhood allergic disease.

Search strategy We searched Medline and all evidence-based medicine reviews for randomised controlled trials comparing the effects of n-3 PUFA and placebo supplementation during pregnancy and/or lactation on childhood allergic diseases and inflammatory cytokines.

Selection criteria We included studies reporting on food allergy, response to the egg skin prick test (SPT), atopy and asthma in infancy and childhood as well as production of interleukin-13 and interferon-gamma (IFN- $\gamma$ ), two cytokines involved in the pathogenesis of asthma. For assessment of inclusion, two authors reviewed all abstracts for suitability and independently extracted data.
Data collection and analysis Two-by-two tables were constructed and odds ratios (OR) were calculated for the outcomes: response to the SPT, food allergy, atopy and asthma in childhood. The assays differed so data on inflammatory markers were reported in narrative form.

Main results Five randomised controlled trials $(n=949)$ were included. n-3 PUFA supplementation during pregnancy reduced 12-month prevalence of positive egg SPT (two trials, 12/87 versus $32 / 100$, OR $0.33,95 \%$ CI $0.16,0.70$ ) and childhood asthma (two trials, $10 / 303$ versus $17 / 179$, OR $0.349,95 \%$ CI $0.154,0.788$ ) and significantly reduced cord blood interleukin-13 levels.

Supplementation during lactation did not prevent asthma, food allergy or atopy.

Conclusion n-3 PUFA supplementation during pregnancy decreases childhood asthma and response to SPT.

Keywords Allergy, meta-analysis, omega-3 polyunsaturated fatty acids, perinatal supplementation.

Please cite this paper as: Klemens C, Berman D, Mozurkewich E. The effect of perinatal omega-3 fatty acid supplementation on inflammatory markers and allergic diseases: a systematic review. BJOG 2011;118:916-925.

\section{Introduction}

The incidence of allergic diseases in the industrialised world has increased significantly over the past $20-40$ years. $^{1}$ One possible explanation for the observed increase involves the concurrent change in Western diet from a relative balance between anti-inflammatory omega- 3 fatty acids (n-3 PUFA) and proinflammatory omega- 6 fatty acids (n-6 PUFA), to a diet in which $n-6$ PUFA are overwhelmingly predominant. ${ }^{1}$

\footnotetext{
* This paper was presented as a poster at The Pregnancy Meeting ${ }^{\mathrm{TM}}$, the 30th Annual Meeting of The Society for Maternal Fetal Medicine (SMFM) in Chicago, Illinois February 2010.
}

Allergic diseases are typically diagnosed in early infancy, further suggesting that causative events take place in utero or during the neonatal period. ${ }^{2}$ Investigators have speculated that the predisposition to allergic disease may result from insufficiently balanced $\mathrm{T}$ helper cell type 1 and 2 (Th1 and Th2) pathways during fetal life. ${ }^{3}$

It has been proposed that high concentrations of dietary n-6 PUFA favour a Th2 differentiation of the immune system during ontogeny and development. ${ }^{1}$ One mechanism whereby n-3 PUFA may alter the $\mathrm{T}$ helper cell balance is through suppression of interleukin-13 (IL-13) production. Interleukin-13 may be related to allergic diseases through its role in inducing immunoglobulin $\mathrm{E}$ (IgE) synthesis in 
B cells and Th2 type differentiation in T cells. ${ }^{4}$ Likewise, aberrant or reduced expression of the cytokine, interferongamma (IFN- $\gamma)$ has also been associated with a number of autoinflammatory and autoimmune diseases. ${ }^{5,6}$

It is now known that immunological abnormalities precede the development of allergic disease. ${ }^{2}$ Additionally, the immature immune system is highly susceptible to immunomodulatory environmental conditions, particularly in the prenatal and postnatal periods. ${ }^{1}$ It has been hypothesised that maternal diet may impact neonatal immune development and subsequently alter allergic responses of neonates. Specifically, maternal intake of n-3 PUFA has been implicated; animal and human studies support the hypothesis that $\mathrm{n}-3$ PUFA suppress cell-mediated immune responses. ${ }^{7}$

Docosahexaenoic acid (DHA) and eicosapentaenoic acid (EPA) are two biologically active n-3 PUFA with major immunomodulatory functions. High intake of n-3 PUFA decreases the proportion of arachidonic acid (AA) in immune cell membranes and subsequently decreases cell responsiveness to exogenous stimuli. The DHA and EPA competitively inhibit the metabolism of $\mathrm{AA}$, resulting in reduced production of the 'pro-allergic' four-series leukotrienes and the two-series prostaglandins. n-3 PUFA are also known to inhibit the activation of proinflammatory cell signals. ${ }^{1}$

The known biological activities of n-3 PUFA have led investigators to hypothesise that supplementation during pregnancy and lactation may serve as a method of primary prevention of allergic diseases in childhood. This systematic review synthesises the results of several randomised controlled trials that have investigated the effects of maternal supplementation with n-3 PUFA during pregnancy and/or lactation for primary prevention of food allergy, atopy (atopic dermatitis), and asthma in neonates, infants and children.

\section{Methods}

\section{Search strategy}

We identified relevant studies by a computer search of MEDLINE and MEDLINE In-Process databases for the years 1950 to October 2010. We included In-Process and Other Non-Indexed Citations available in MEDLINE up to 21 October 2010. We also searched all EBM reviews, which included Cochrane Database of Systematic Reviews, ACP Journal Club, DARE, CCTR, CMR, HTA and NHSEED. The searches were conducted using combinations of the following medical subject heading terms: 'polyunsaturated fatty acids', 'n-3 PUFA', 'omega 3 fatty acids', 'DHA', 'EPA', 'fish oil', 'pregnancy', 'lactation', 'allergy', 'atopy', 'dermatitis', 'asthma', 'wheezing' and 'skin prick'. We did not apply a language restriction. We supplemented our search by cross-checking the reference lists of all relevant review articles and by searching by principal investigators' names for secondary analyses of all identified randomised controlled trials. We contacted primary authors for clarification of data when necessary.

\section{Study selection}

We included studies comparing supplementation in pregnancy and lactation with n-3 PUFA or placebo for primary prevention of allergic disease in neonates, infants and children.

\section{Types of studies}

All included studies were randomised controlled trials.

\section{Types of participants}

All included participants were pregnant or lactating women and their offspring. Two of the included studies required a personal or family history of allergic disease for enrolment, ${ }^{8,9}$ whereas three studies did not require any history of risk factors for allergic disease. ${ }^{10-12}$

\section{Types of interventions}

All included studies involved supplementation of pregnant or lactating women with n-3 PUFA or placebo.

\section{Types of outcome measures}

To be included in this systematic review, the studies had to report on one of the following clinical or immunological outcomes in neonates, infants or children: asthma, atopy and food allergy as a clinical diagnosis or as response to the egg skin prick test (SPT) at any time during the first 12 months of life. We included only studies in which diagnoses were verified by medical or nursing clinicians. We also included studies reporting on production of two inflammatory cytokines involved in the allergic response: IL-13 and IFN- $\gamma$.

\section{Validity assessment}

Two reviewers (CK and EM) initially screened the title, abstract and keywords of all 81 articles identified by the searches. The majority of these were excluded because they were not randomised controlled trials. These reviewers then selected 28 potentially relevant articles $^{8-35}$ that corresponded to eight randomised controlled trials and their secondary analyses. Full texts were then independently viewed for further consideration for inclusion. One randomised controlled trial that was available in abstract form was excluded because only interim analysis data were available. ${ }^{33}$ We excluded one additional randomised controlled trial because n-3 PUFA supplementation was initiated after pregnancy and lactation were completed. ${ }^{13-18}$ Finally, we excluded a third randomised controlled trial because the intervention under study, blackcurrant oil, contained a 
mixture of n-6 and n-3 PUFA. ${ }^{35}$ Two reviewers (CK and EM) then independently applied specific inclusion criteria to each of the potentially relevant articles and selected five randomised controlled trials for inclusion. ${ }^{8-12}$ All primary and secondary articles resulting from these trials were carefully reviewed for data on outcomes of interest. Additional data from a published secondary analysis of one of the trials were also included. ${ }^{19}$ All included studies are listed in Table 1 and the flow of studies through the selection process is shown in Figure 1.

\section{Data abstraction and quality assessment}

Included articles were duplicated for independent review by two investigators (CK and EM) and data from each outcome were independently extracted into two-by-two tables in 'events/totals' form for supplemented and control groups. Discrepancies were resolved by repeat manuscript review and discussion until consensus was reached. In one instance, an original author, Dr Lauritzen, was contacted for clarification of data. For the cytokines of interest, mean levels with 95\% confidence intervals and significance levels were extracted. Both reviewers independently assigned a quality score to each included article based on the Scottish Intercollegiate Guidelines Network scoring system for randomised controlled trials. ${ }^{36}$ Individual elements that contributed to the quality score included a clearly focused research question, randomisation, allocation concealment, blinding, analysis of drop-outs and follow up, standardised measurement of outcomes, intention-to-treat analysis, and similar baseline characteristics in the treatment and control groups.

\section{Study characteristics}

Five randomised controlled trials with 949 participants were included in this systematic review. All the included studies were of high methodological quality. Four of the included studies initiated n-3 PUFA supplementation during pregnancy $8,9,11,12,19$ whereas one study began the supplementation during lactation. ${ }^{10}$ Four of the included studies reported on clinical outcomes ${ }^{8-10,12}$ and one reported on inflammatory cytokines only. ${ }^{11}$ The included studies are summarised in Table 1.

\section{Quantitative data synthesis}

Summary odds ratios (OR) were calculated using the fixed effects method and confirmed using the random effects method. By convention, an odds ratio of less than 1 indicated that the event was more likely in the control group. Between-study heterogeneity was assessed using Cochran's chi-square test $(Q)$ and confirmed using the $I$-squared test because of the small number of studies included for some outcome comparisons. ${ }^{37}$ Heterogeneity was considered significant at an alpha level of $<0.05$. We conducted prespecified subgroup analyses according to time of initiation of n-3 supplementation (i.e. during pregnancy or lactation). There were not enough extant studies to conduct subgroup

Table 1. Characteristics of included studies

\begin{tabular}{|c|c|c|c|c|c|}
\hline & Dunstan $^{8,19}$ & Lauritzen $^{10}$ & Krauss-Etschmann ${ }^{11}$ & Olsen $^{12}$ & Furuhjelm ${ }^{9}$ \\
\hline Year & 2003 & 2005 & 2008 & 2008 & 2009 \\
\hline Quality & High & High & High & High & High \\
\hline Follow up & $83 / 98(85 \%)$ & $72 / 147(49 \%)$ & $141 / 157(90 \%)$ & $399 / 402(99 \%)$ & $117 / 145(81 \%)$ \\
\hline Intervention & $\begin{array}{l}\text { Fish oil; } 3.7 \text { g/day } \\
\text { n-3 PUFA }\end{array}$ & $\begin{array}{l}\text { Fish oil; } 1.5 \text { g/day } \\
\text { n-3 LCPUFA }\end{array}$ & $\begin{array}{l}\text { Fish oil; } 0.5 \mathrm{~g} / \text { day } \\
\text { DHA + } 0.15 \mathrm{~g} / \text { day } \\
\text { EPA }\end{array}$ & $\begin{array}{l}\sim 2.7 \mathrm{~g} / \text { day marine } \\
\mathrm{n}-3 \text { PUFA }+2 \mathrm{mg} \\
\text { tocopherol } / \mathrm{ml}\end{array}$ & $\begin{array}{l}1.6 \mathrm{~g} / \text { day EPA + } \\
1.1 \mathrm{~g} / \text { day DHA + } \\
23 \mathrm{mg} \alpha \text {-tocopherol }\end{array}$ \\
\hline Control & Olive oil & Olive oil & Placebo not described & Olive oil & $\begin{array}{l}\text { Soy oil; } 2.5 \text { g/day } \omega-6 \\
\text { PUFA LA + } \\
0.28 \mathrm{~g} / \text { day } \omega-3 \\
\text { PUFA LNA + } 36 \mathrm{mg} \\
\alpha \text {-tocopherol }\end{array}$ \\
\hline Total no. & 98 & 147 & 157 & 402 & 145 \\
\hline $\begin{array}{l}\text { Duration of } \\
\text { intervention }\end{array}$ & $\begin{array}{l}\text { From week } 20 \text { of } \\
\text { gestation until } \\
\text { delivery }\end{array}$ & $\begin{array}{l}\text { First } 4 \text { months of } \\
\text { lactation }\end{array}$ & $\begin{array}{l}\text { From week } 22 \text { of } \\
\text { gestation until } \\
\text { delivery }\end{array}$ & $\begin{array}{l}\text { From week } 30 \text { of } \\
\text { gestation until } \\
\text { delivery }\end{array}$ & $\begin{array}{l}\text { From week } 25 \text { of } \\
\text { gestation through } \\
\text { pregnancy and } \\
\text { lactation }\end{array}$ \\
\hline $\begin{array}{l}\text { Length of } \\
\text { follow up }\end{array}$ & 12 months & 30 months & Delivery & 16 years & 12 months \\
\hline Outcomes & $\begin{array}{l}\text { Asthma, food allergy, } \\
\text { atopic dermatitis, skin } \\
\text { prick test, IL-13, IFN- } \gamma\end{array}$ & $\begin{array}{l}\text { Asthma, food allergy, } \\
\text { atopic dermatitis, } \\
\text { IFN- } \gamma\end{array}$ & IL-13, IFN- $\gamma$ & Asthma & $\begin{array}{l}\text { Food allergy, atopic } \\
\text { dermatitis, } \\
\text { skin prick test }\end{array}$ \\
\hline
\end{tabular}




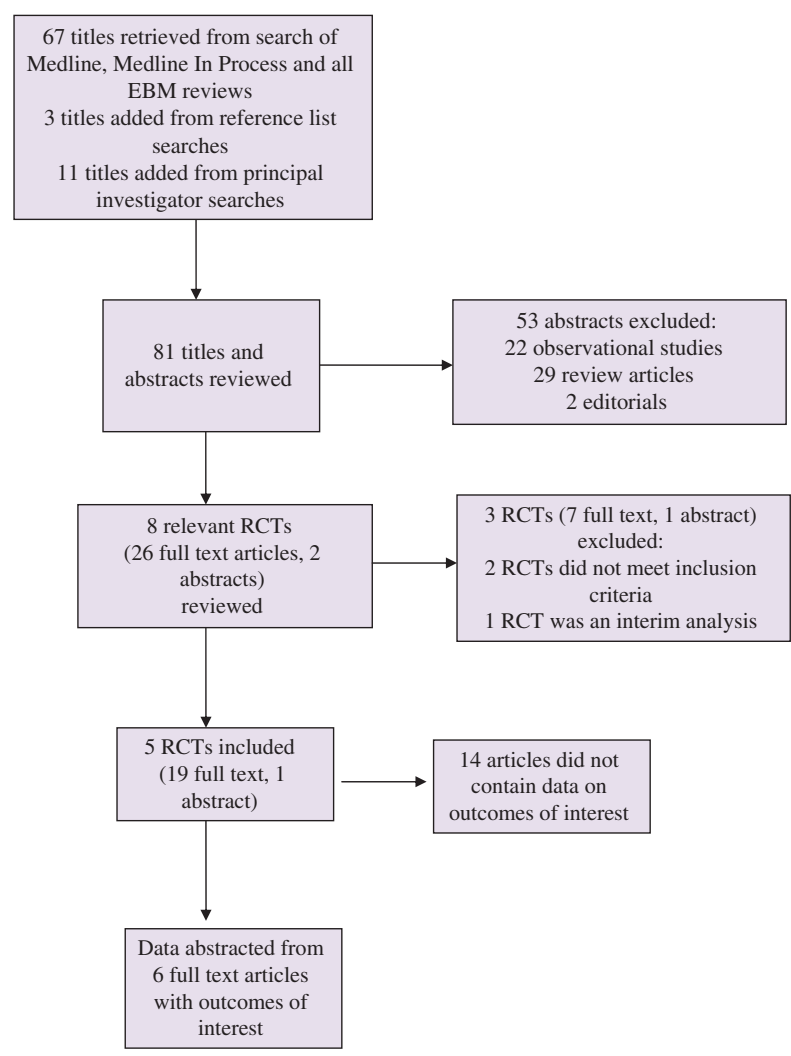

Figure 1. Summary of stages of study inclusion and exclusion for the meta-analysis; RCT, randomised controlled trial.

analyses according to risk status of participants. We assessed the studies for publication bias by constructing funnel plots and assessing for asymmetry as described by Egger et al. ${ }^{38}$ Egger's regression intercept test was used to quantify the bias captured by the funnel plot. Evidence of asymmetry was specified at a significance level of $P<0.1$. We carried out all statistical analyses and generated all Forrest plots using Comprehensive Meta-Analysis, version 2.0, 2006, Englewood, NJ.

In the included studies, IL-13 and IFN- $\gamma$ production were reported using different assays and units that precluded statistical combination. Therefore we reported results for these outcomes of interest in narrative form.

\section{Results}

Three of the included studies $(n=264)$ reported on clinical diagnoses of food allergy in children. ${ }^{8-10}$ There was no significant difference in food allergy between children of mothers who received n-3 PUFA supplementation and children of mothers receiving placebo (6/128 versus $16 / 136$, OR 0.462 , 95\% CI $0.155,1.377$; Figure 2 ). When only studies in which supplementation was started during pregnancy ${ }^{8,9}$ were considered, there were fewer children with food allergies born to n-3 PUFA-supplemented mothers than to placebo-supplemented mothers, but this difference was not significant (4/92 versus 15/108, OR 0.341, 95\% CI $0.101,1.153)$. For the total analysis, there was no significant between-study heterogeneity $(Q=2.975, d f 2, P=0.226$, $\left.I^{2}=32.777\right)$ nor was there evidence of publication bias (Egger's regression intercept $P=0.998)$.

Two of the included studies $(n=187)$ reported on the period prevalence of positive response to the egg SPT in children up to 12 months old after maternal n-3 PUFA supplementation during pregnancy. ${ }^{8,9}$ Supplementation significantly reduced a positive SPT response to egg $(12 / 87$ versus 32/100, OR 0.332, 95\% CI 0.158, 0.700; Figure 3). There was no significant between-study heterogeneity $\left(Q=0.003, d f 1, P=0.957, I^{2}=0.000\right)$. There were too few included studies to assess publication bias.

We included three studies $(n=262)$ that reported on atopy (eczema or atopic dermatitis) in children after maternal n-3 PUFA supplementation during pregnancy and lactation. $^{8-10}$ There was no difference in atopic dermatitis between children born to mothers receiving n-3 PUFA or placebo (27/128 versus 32/134, OR 0.924, 95\% CI 0.488, 1.750; Figure 4). This result was not different when the one study ${ }^{10}$ that commenced supplementation during lactation was excluded. There was significant between-study heterogeneity for this comparison $(Q=6.731$, df $2, P=0.035$, $I^{2}=70.287$ ), but there was no evidence of publication bias

\begin{tabular}{|c|c|c|c|c|c|c|c|c|}
\hline \multirow[t]{2}{*}{ Study name } & \multicolumn{5}{|c|}{ Statistics for each study } & \multicolumn{3}{|c|}{ Odds ratio and $95 \% \mathrm{Cl}$} \\
\hline & $\begin{array}{l}\text { Odds } \\
\text { ratio }\end{array}$ & $\begin{array}{l}\text { Lower } \\
\text { limit }\end{array}$ & $\begin{array}{l}\text { Upper } \\
\text { limit }\end{array}$ & $Z$-value & $p$-value & & & \\
\hline Dunstan 2003 & 0.616 & 0.137 & 2.765 & -0.632 & 0.527 & & & \\
\hline Lauritzen 2005 & 1.588 & 0.137 & 18.461 & 0.370 & 0.712 & & & \\
\hline Furuhjelm 2009 & 0.108 & 0.013 & 0.872 & -2.088 & 0.037 & & & \\
\hline Summary & 0.462 & 0.155 & 1.377 & -1.386 & 0.166 & & & \\
\hline & & & & & & 0.01 & 0.1 & 100 \\
\hline
\end{tabular}

Figure 2. Odds ratio and $95 \%$ confidence intervals for food allergy outcomes. 


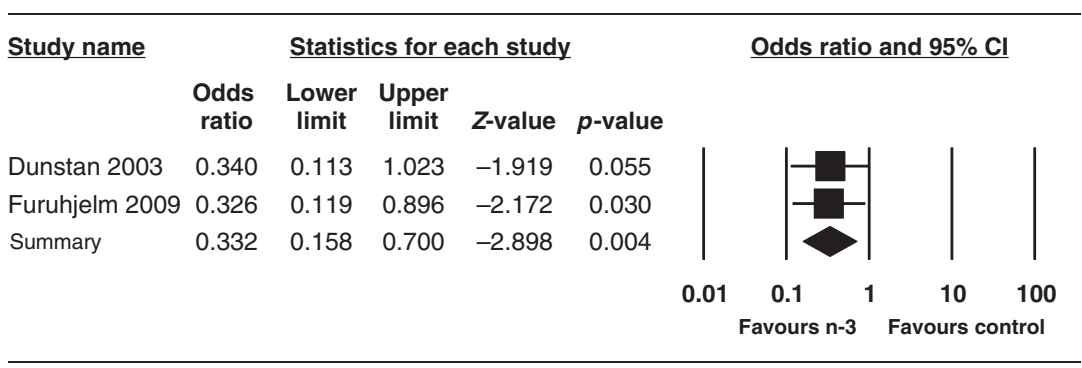

Figure 3. Odds ratio and $95 \%$ confidence intervals for skin prick outcomes.

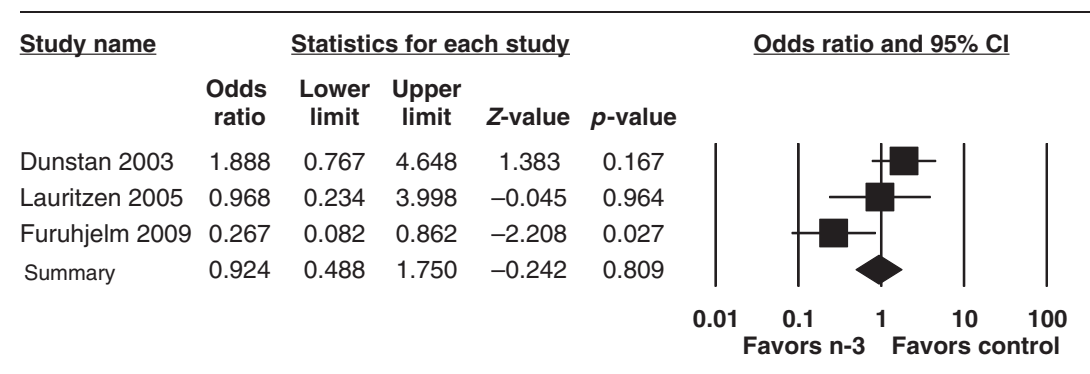

Figure 4. Odds ratio and $95 \%$ confidence intervals for atopy outcomes.

for this comparison (Egger's regression intercept $P=0.627)$.

Three of the included studies $(n=546)$ reported on the outcome of asthma in children after supplementation during pregnancy or lactation. ${ }^{8,10,12}$ In the analysis of all studies combined, there was no difference in asthma between children in the n-3 PUFA-supplemented and placebo groups (21/339 versus 23/207, OR 0.583 , 95\% CI 0.300 , 1.133; Figure 5). However, in the analysis of the two studies in which supplementation was initiated during pregnancy, ${ }^{8,12}$ n-3 PUFA supplementation significantly reduced asthma during childhood (10/303 versus $17 / 179$, OR 0.349 , $95 \%$ CI $0.154,0.788)$. In the total analysis, there was no significant between-study heterogeneity. ( $Q=4.559$, df 2 , $\left.P=0.102, I^{2}=56.126\right)$, nor was there evidence of publication bias (Egger's regression intercept $P=0.98$ ).
Two of the included studies reported decreased IL-13 production in the cord blood of infants born to women receiving n-3 PUFA compared with women receiving placebo. ${ }^{11,19}$ These outcome values could not be statistically combined because of the differing assays and units of reporting. Dunstan et al. ${ }^{19}$ reported that maternal n-3 PUFA supplementation significantly reduced IL-13 levels as measured by ELISA $(P<0.05)$. Krauss-Etschmann et al. ${ }^{11}$ measured mRNA for IL-13 and reported that IL-13 mRNA levels were significantly reduced in the n-3 PUFA group compared with placebo $(P<0.05)$.

The three included studies that reported on IFN- $\gamma$ levels in neonates or infants reported differing effects of supplementation on IFN- $\gamma \cdot{ }^{10,11,19}$ Dunstan et al. ${ }^{19}$ found no difference in IFN- $\gamma$ response in cord blood; however, levels of IFN- $\gamma$ were below detection in more than $95 \%$ of

\begin{tabular}{|c|c|c|c|c|c|c|c|}
\hline \multirow[t]{2}{*}{ Study name } & \multicolumn{6}{|c|}{ Statistics for each study } & \multirow[t]{2}{*}{ Odds ratio and $95 \% \mathrm{Cl}$} \\
\hline & $\begin{array}{l}\text { Odds } \\
\text { ratio }\end{array}$ & $\begin{array}{l}\text { Lower } \\
\text { limit }\end{array}$ & $\begin{array}{l}\text { Upper } \\
\text { limit }\end{array}$ & $Z$-value & $p$-value & & \\
\hline Dunstan 2003 & 0.325 & 0.062 & 1.712 & -1.326 & 0.185 & & \\
\hline Lauritzen 2005 & 1.613 & 0.512 & 5.085 & 0.817 & 0.414 & & \\
\hline Olsen 2008 & 0.357 & 0.140 & 0.909 & -2.161 & 0.031 & & \\
\hline \multirow[t]{3}{*}{ Summary } & 0.583 & 0.300 & 1.133 & -1.593 & 0.111 & & \\
\hline & & & & & & 0.01 & 0.1 \\
\hline & & & & & & & Favors n-3 Favors control \\
\hline
\end{tabular}

Figure 5. Odds ratio and 95\% confidence intervals for asthma outcomes. 
samples. Lauritzen et al. ${ }^{10}$ reported that lipopolysaccharide induced IFN- $\gamma$ was significantly greater in the n-3 PUFAsupplemented group compared with the controls at 2.5 years of age. By contrast, Krauss-Etschmann ${ }^{11}$ found no difference in IFN- $\gamma$ in cord blood.

\section{Comment}

We conducted a systematic review of recent studies to identify the role that perinatal n-3 PUFA supplementation plays in infant and childhood allergy, asthma, atopy and inflammatory markers. We found that maternal n-3 PUFA supplementation during pregnancy significantly reduced the prevalence of positive egg SPT in infants up to 12 months old as well as the prevalence of childhood asthma, but had no effect on childhood atopy (atopic dermatitis). In children whose mothers received prenatal n-3 PUFA supplementation, there was a non-significant trend towards reduction in clinical food allergy. Based on the odds ratios from the included studies, the reduction in food allergies might be as high as $66 \%$; however, given the small sample and wide confidence intervals, further studies are needed to test this hypothesis. Prenatal n-3 PUFA supplementation significantly reduced fetal IL-13 production. In contrast prenatal supplementation did not alter IFN- $\gamma$.

Included studies were assessed and rated by two independent evaluators. The high methodological quality of these included studies was a source of strength in this meta-analysis. Four of the five included studies had followup data for $80 \%$ of the children of supplemented mothers, another index of high methodological quality. ${ }^{39}$ Data were analysed both with and without the study that commenced supplementation during lactation. ${ }^{10}$ In general, this study showed less of a trend toward benefit for most of the studied clinical outcomes than the studies in which supplementation was initiated during pregnancy. However, inclusion of this study did not alter the conclusions of the analysis, except for the outcome of childhood asthma.

The administration of n-3 fatty acids was found to significantly reduce childhood asthma in the analysis of studies in which supplementation was initiated during pregnancy but not in the combined analysis. This result was heavily influenced by the Olsen study, which used an olive oil placebo. ${ }^{12}$ This leads to the question of whether olive oil supplementation during pregnancy might increase the risk for asthma, incorrectly suggesting a benefit for $n-3$ fatty acids. A recently published cohort study, however, suggests that a diet rich in olive oil during pregnancy may itself prevent childhood asthma, ${ }^{40}$ so it is more likely that the placebo in the Olsen study may have tended to mask a beneficial effect of the $\mathrm{n}-3$ fatty acid supplementation.

Several potential limitations of our analysis need to be noted. First, the trials included participants from Sweden, Denmark, Hungary, Western Australia, Norway, Germany and Spain. This may limit the generalisability of the results or may, conversely, underestimate the magnitude of benefit of supplementation by studying women who already have a moderate baseline n-3 PUFA intake. Variation in the dietary habits between countries may result in considerable differences in baseline fatty acid states and subsequent responses to supplementation. For example, one included study took place in Sweden ${ }^{9}$ where the n-3 PUFA to $n-6$ PUFA ratio is approximately $5: 1^{34}$ in contrast to many other Western countries in which it is estimated to be between 20:1 and 30:1. ${ }^{41}$ The women's diets in any one study may not necessarily represent those of other Western populations.

Second, the different doses of supplementation in the combined studies may also represent a weakness of this meta-analysis, given that n-3 PUFA supplementation may have an inverted $U$-shaped dose-response curve, with moderate doses conferring more benefit than high doses in some models. ${ }^{42}$ Likewise, the relatively small number of extant studies and small sample sizes limited the precision of our estimates.

Finally, although a positive SPT indicates the presence of food-specific IgE antibodies, ${ }^{43}$ a positive response may be seen in tolerant individuals and does not necessarily represent food allergy. ${ }^{44}$ Although we found a significant reduction in this intermediate outcome measure, future randomised controlled trials of prenatal n-3 fatty acid supplementation are needed to assess the effect on clinical allergic disease as well as the durability of any beneficial effects.

Our study differed from the previously published systematic review of n-3 and n-6 PUFA supplementation for primary prevention of allergic disease ${ }^{45}$ in that we included only studies of perinatal n-3 PUFA supplementation and excluded studies of n-6 PUFA supplementation. Anandan et al. ${ }^{45}$ included studies of fortification of infant formula and diet in early childhood, and it is possible that this relatively late initiation of supplementation accounts for the lack of trend toward benefit in their analysis. That finding is in accord with the results of the included Lauritzen et al. trial $^{10}$ that began $n-3$ PUFA supplementation during lactation, as well as the excluded Mihrshahi et al. trial, ${ }^{14}$ which began infant $n-3$ supplementation after the conclusion of pregnancy and lactation. In addition, our study included the Furuhjelm study, which was published subsequent to the search date of the Anandan et al. systematic review. ${ }^{9,45}$

More studies are needed before any clinical recommendations can be made regarding the benefit of n-3 PUFA supplementation in decreasing childhood allergy. This would allow for appropriate comparisons among women exposed to varying dietary patterns and examination of the impact of supplementation duration and dosage. The n-6 to n-3 PUFA ratio status of study participants 
needs to be taken into account when designing future studies. Decreasing n-6 PUFA in the diet while supplementing with n-3 PUFA may prove to be maximally effective in stabilising this ratio.

It is also important to consider the safety of supplementation, especially in pregnant populations. Fish oil does have a potential antithrombotic effect, although available clinical trial evidence does not demonstrate any increased risk for bleeding at delivery after prenatal fish oil supplementation. ${ }^{46,47}$ Fish oil supplementation may also prolong gestational length by 2.6 days on average, which may be considered beneficial or harmful, depending on circumstance. ${ }^{46}$ Other potential risks with fish oil supplementation are fatty acid oxidation, hypervitaminosis and exposure to environmental toxins; these risks can be minimised by rigorous purification. ${ }^{48}$ In assessing the overall risk to benefit trade-offs during pregnancy it should be noted that in a recent large randomised controlled trial, compared with placebo, prenatal n-3 PUFA supplementation reduced serious fetal/neonatal adverse events, defined as death, major congenital anomaly, hospital treatment, or admission to a neonatal intensive care unit. ${ }^{47}$

Our analysis found differing effects on allergic diseases when supplementation was started during pregnancy compared with during lactation. Fetal immune responses to antigens have been detected as early as the 22nd week of gestation; ${ }^{6}$ the results of our analysis support the hypothesis that supplementation in the postnatal period may be too late to modify the allergic response. Future large randomised controlled trials to explore the role of supplementation during pregnancy should begin in early gestation, at least before 25 weeks. Such research should pay careful attention to optimal dosages and allow for extended follow up so that the effect on long-term allergic disease outcomes can be determined. Preventative approaches are needed to reduce the significant health burden of asthma and allergy, which are among the most common chronic diseases worldwide, affecting one in three children. ${ }^{49}$ If the role of maternal n-3 PUFA supplementation on neonatal and childhood allergy and atopy children is established, there may be an opportunity for healthcare providers to recommend maternal n-3 PUFA supplementation for the primary prevention of allergic disease.

\section{Conclusion}

Our systematic review demonstrates that n-3 PUFA supplementation during pregnancy decreases childhood asthma and response to SPT, while supplementation begun during lactation does not significantly alter these clinical outcomes. Supplementation with n-3 PUFA also reduces IL-13 in cord blood, indicating prenatal modulation of the immune response that may lead to allergic diseases in childhood.
Large randomised trials are needed to confirm the preventative effects of prenatal n-3 PUFA supplementation on allergic diseases of childhood.

\section{Disclosure of interests}

The authors have no personal or financial interests in the topic involved in this work.

\section{Contribution to authorship}

CMK and ELM conducted the literature search, reviewed all titles, abstracts and full text manuscripts and independently assessed them for suitability for inclusion. Both of them assigned quality scores to each included manuscript. CMK and ELM independently extracted data on study outcomes. ELM performed the data syntheses and CMK, DRB and ELM wrote the manuscript.

\section{Details of ethics approval}

This work did not involve the collection of any original data and so did not require ethics approval.

\section{Funding}

No funding was received.

\section{References}

1 Blumer N, Renz H. Consumption of omega3-fatty acids during perinatal life: role in immuno-modulation and allergy prevention. $J$ Perinat Med 2007;35(Suppl 1):S12-18.

2 Prescott SL, Dunstan JA. Prenatal fatty acid status and immune development: the pathways and the evidence. Lipids 2007;42:80110.

3 Schaub B, Liu J, Höppler S, Haug S, Sattler C, Lluis A, et al. Impairment of T-regulatory cells in cord blood of atopic mothers. J Allergy Clin Immunol 2008;121:1491-9.

4 Heinzmann A, Mao XQ, Akaiwa M, Kreomer RT, Gao PS, Ohshima $\mathrm{K}$, et al. Genetic variants of IL-13 signalling and human asthma and atopy. Hum Mol Genet 2000;9:549-59.

5 Schoenborn JR, Wilson CB. Regulation of interferon-gamma during innate and adaptive immune responses. Adv Immunol 2007;96:41101.

6 Warner JA, Jones CA, Jones AC, Warner JO. Prenatal origins of allergic disease. J Allergy Clin Immunol 2000;105:S493-8.

7 Simopoulos AP. Omega-3 fatty acids in inflammation and autoimmune diseases. J Am Coll Nutr 2002;21:495-505.

8 Dunstan JA, Mori TA, Barden A, Beilin L, Taylor AL, Holt PG, et al. Fish oil supplementation in pregnancy modifies neonatal allergenspecific immune responses and clinical outcomes in infants at high risk of atopy: a randomized, controlled trial. J Allergy Clin Immunol 2003;112:1178-84.

9 Furuhjelm C, Warstedt K, Larsson J, Fredriksson M, Bottcher MF, Falth-Magnusson $\mathrm{K}$, et al. Fish oil supplementation in pregnancy and lactation may decrease the risk of infant allergy. Acta Paediatr 2009;98:1461-7.

10 Lauritzen L, Kjaer TM, Fruekilde MB, Michaelsen KF, Frokiaer H. Fish oil supplementation of lactating mothers affects cytokine production in 21/2-year-old children. Lipids 2005;40:669-76. 
11 Krauss-Etschmann S, Hartl D, Rzehak P, Heinrich J, Shadid R, Del Carmen Ramirez-Tortosa M, et al. Decreased cord blood IL-4, IL-13, and CCR4 and increased TGF-beta levels after fish oil supplementation of pregnant women. J Allergy Clin Immunol 2008;121:464470.e6..

12 Olsen SF, Osterdal ML, Salvig JD, Mortensen LM, Rytter D, Secher $\mathrm{NJ}$, et al. Fish oil intake compared with olive oil intake in late pregnancy and asthma in the offspring: 16 y of registry-based followup from a randomized controlled trial. Am J Clin Nutr 2008;88: 167-75.

13 Mihrshahi S, Peat JK, Webb K, Tovey ER, Marks GB, Mellis CM, et al. The childhood asthma prevention study (CAPS): design and research protocol of a randomized trial for the primary prevention of asthma. Control Clin Trials 2001;22:333-54.

14 Mihrshahi S, Peat JK, Marks GB, Mellis CM, Tovey ER, Webb K, et al. Eighteen-month outcomes of house dust mite avoidance and dietary fatty acid modification in the childhood asthma prevention study (CAPS). J Allergy Clin Immunol 2003;111:162-8.

15 Peat JK, Mihrshahi S, Kemp AS, Marks GB, Tovey ER, Webb K, et al. Three-year outcomes of dietary fatty acid modification and house dust mite reduction in the Childhood Asthma Prevention Study. J Allergy Clin Immunol 2004;114:807-13.

16 Marks GB, Mihrshahi S, Kemp AS, Tovey ER, Webb K, Almqvist C, et al. Prevention of asthma during the first 5 years of life: a randomized controlled trial. J Allergy Clin Immunol 2006;118:53-61.

17 Almqvist C, Garden F, Xuan W, Mihrshahi S, Leeder SR, Oddy W, et al. Omega-3 and omega- 6 fatty acid exposure from early life does not affect atopy and asthma at age 5 years. J Allergy Clin Immunol 2007;119:1438-44.

18 Mihrshahi S, Webb K, Almqvist C, Kemp AS, CAPS Team. Adherence to allergy prevention recommendations in children with a family history of asthma. Pediatr Allergy Immunol 2008;19:355-62.

19 Dunstan JA, Mori TA, Barden A, Beilin L, Taylor AL, Holt PG, et al. Maternal fish oil supplementation in pregnancy reduces interleukin13 levels in cord blood of infants at high risk of atopy. Clin Exp Allergy 2003;33:442-8.

20 Hatfield HM, Dunstan JA, Hayes L, Sehmi R, Holt PM, Denberg JA, et al. Dietary N-3 polyunsaturated fatty acid (PUFA) supplementation during pregnancy is associated with changes in cord blood (CB) progenitor numbers and responsiveness to IL-5 in infants at risk of atopy [abstract]. J Allergy Clin Immunol 2003;2(Suppl):S320.

21 Barden AE, Mori TA, Dunstan JA, Taylor AL, Thornton CA, Croft KD, et al. Fish oil supplementation in pregnancy lowers F2-isoprostanes in neonates at high risk of atopy. Free Radic Res 2004;38:233-9.

22 Denburg JA, Hatfield HM, Cyr MM, Hayes L, Holt PG. Fish oil supplementation in pregnancy modifies neonatal progenitors at birth in infants at risk of atopy. Pediatr Res 2005;57:276-81.

23 Barden AE, Dunstan JA, Beilin LJ, Prescott SL, Mori TA. n-3 fatty acid supplementation during pregnancy in women with allergic disease: effects on blood pressure, and maternal and fetal lipids. Clin Sci (Lond) 2006;111:289-94.

24 Prescott SL, Barden AE, Mori TA, Dunstan JA. Maternal fish oil supplementation in pregnancy modifies neonatal leukotriene production by cord-blood-derived neutrophils. Clin Sci (Lond) 2007; 113:409-16.

25 Prescott SL, Irvine J, Dunstan JA, Hii C, Ferrante A. Protein kinase Czeta: a novel protective neonatal T-cell marker that can be upregulated by allergy prevention strategies. I Allergy Clin Immunol 2007:20:200-6.

26 Dunstan JA, Mitoulas LR, Dixon G, Doherty DA, Hartmann PE, Simmer $\mathrm{K}$, et al. The effects of fish oil supplementation in pregnancy on breast milk fatty acid composition over the course of lactation: a randomized controlled trial. Pediatr Res 2007;62:689-94.
27 Dunstan JA, Simmer K, Dixon G, Prescott SL. Cognitive assessment of children at age $2 \frac{1}{2}$ years after maternal fish oil supplementation in pregnancy: a randomised controlled trial. Arch Dis Child Fetal Neonatal Ed 2008;93:F45-50.

28 Lauritzen L, Jørgensen MH, Olsen SF, Straarup EM, Michaelsen KF. Maternal fish oil supplementation in lactation: effect on developmental outcome in breast-fed infants. Reprod Nutr Dev 2005;45: 535-47.

29 Larnkjaer A, Christensen JH, Michaelsen KF, Lauritzen L. Maternal fish oil supplementation during lactation does not affect blood pressure, pulse wave velocity, or heart rate variability in 2.5-year-old children. J Nutr 2006;136:1539-44.

30 Asserhøj M, Nehammer S, Matthiessen J, Michaelsen KF, Lauritzen L. Maternal fish oil supplementation during lactation may adversely affect long-term blood pressure, energy intake, and physical activity of 7-year-old boys. J Nutr 2009;139:298-304.

31 Krauss-Etschmann S, Shadid R, Campoy C, Hoster E, Demmelmair $H$, Jiménez $M$, et al. Effects of fish-oil and folate supplementation of pregnant women on maternal and fetal plasma concentrations of docosahexaenoic acid and eicosapentaenoic acid: a European randomized multicenter trial. Am J Clin Nutr 2007;85:1392-400.

32 Olsen SF, Sørensen JD, Secher NJ, Hedegaard M, Henriksen TB, Hansen HS, et al. Randomised controlled trial of effect of fish-oil supplementation on pregnancy duration. Lancet 1992;339: 1003-7.

33 Romieu I, BarrazaVillarreal A, HernandezCadena L, EscamillaNunez C, Sly P, Neulfeld L, et al.. Supplementation with omega-3 fatty acids and atopy symptoms in infants: a randomized controlled trial [abstract]. European Respiratory Society Annual Congress, Berlin, Germany, 4-8 October 2008.

34 Warstedt K, Furuhjelm C, Duchen K, Falth-Magnusson K, Fageras $M$. The effects of omega- 3 fatty acid supplementation in pregnancy on maternal eicosanoid, cytokine, and chemokine secretion. Pediatr Res 2009;66:212-17.

35 Linnamaa P, Savolainen J, Koulu L, Tuomasjukka S, Kallio H, Yang B, et al. Blackcurrant seed oil for prevention of atopic dermatitis in newborns: a randomized, double-blind, placebo-controlled trial. Clin Exp Allergy 2010;40:1113-15.

36 Scottish Intercollegiate Guidelines Network. Critical appraisal: notes and checklists. 2010 [www.sign.ac.uk/methodology/checklists.html]. Last accessed 22 May 2010.

37 Higgins JP, Thompson SG. Quantifying heterogeneity in a meta-analysis. Stat Med 2002;21:1539-58.

38 Egger $M$, Smith GD, Schneider $M$, Minder C. Bias in meta-analysis detected by a simple, graphical test. BMJ 1997;315:629-34.

39 Oxford centre for evidence-based medicine - levels of evidence (March 2009) [www.cebm.net/?o=1025]. Last accessed 3 January 2010.

40 Castro-Rodriguez JA, Garcia-Marcos L, Sanchez-Solis M, Pérez-Fernández $\mathrm{V}$, Martinez-Torres A, Mallol J. Olive oil during pregnancy is associated with reduced wheezing during the first year of life of the offspring. Pediatr Pulmonol 2010;45:395-402.

41 Simopoulos AP. Essential fatty acids in health and chronic disease. Am J Clin Nutr 1999;70(suppl):560S-9S.

42 Berman DR, Mozurkewich E, Liu Y, Barks J. Docosahexaenoic acid pretreatment confers neuroprotection in a rat model of perinatal cerebral hypoxia-ischemia. Am J Obstet Gynecol 2009;200:305.e1-6.

43 Bock SA, Buckley J, Holst A, May CD. Proper use of skin tests with food extracts in diagnosis of hypersensitivity to food in children. Clin Allergy 1977;7:375-83.

44 Hill $D$, Heine $R$, Hosking $C$. The diagnostic value of skin prick testing in children with food allergy. Pediatr Allergy Immunol 2004;15:43541. 
45 Anandan C, Nurmatov U, Sheikh A. Omega 3 and 6 oils for primary prevention of allergic disease: systematic review and meta-analysis. Allergy 2009;64:840-8.

46 Makrides M, Duley L, Olsen SF. Marine oil, and other prostaglandin precursor, supplementation for pregnancy uncomplicated by preeclampsia or intrauterine growth restriction. Cochrane Database of Systematic Reviews 2006, Issue 3. Art. No.: CD003402. DOI:10.1002/ 14651858.CD003402.pub2.

47 Makrides M, Gibson RA, McPhee AJ, Yelland L, Quinlivan J, Ryan P, et al. Effect of DHA supplementation during pregnancy on maternal depression and neurodevelopment of young children: a randomized controlled trial. JAMA 2010;304:1675-83.

48 Bays HE. Safety considerations with omega-3 fatty acid therapy. Am J Cardiol 2007;99:35C-43C.

49 Bousquet J, Burney PG, Zuberbier T, Cauwenberge PV, Akdis CA, Bindslev-Jensen C, et al. GA2LEN (Global Allergy and Asthma European Network) addresses the allergy and asthma 'epidemic'. Allergy 2009;64:969-77

\section{Commentary on fetal programming: role of fish oil in pregnancy for the prevention of asthma and allergies in the offspring}

Two decades ago David Barker and colleagues published their first reports showing that an individual's risk of developing ischaemic heart disease or metabolic syndrome in adult life is inversely related to his or her own birthweight (Barker et al., Lancet 1989;2:577-80; Barker et al., BMJ 1991;303:1019-22). Around the same time, albeit a little later, another group headed by Ekbom and Trichopoulos published their equally astonishing observations suggesting that high birthweight is a risk factor for, and maternal pre-eclampsia a protective factor against, breast cancer (Ekbom et al., Lancet 1992;340:1015-18). It was such epidemiological observations of relatively strong associations between obstetric and perinatal variables on the one hand and of certain chronic diseases that develop many years later on the other that-backed by complementary findings from animal experiments-laid the foundation for the theory that became widely known as the fetal programming or intrauterine origins hypothesis. This postulates the existence of time windows in the early periods of any individual's life when there may be plasticity and susceptibility for insults or influences that latently (i.e. without necessarily leaving any immediately apparent marks on the individual) may determine that person's propensity for developing specific diseases many years later. The fetal programming hypothesis has led to an immense interest in what is traditionally regarded as the field 'belonging to' obstetricians and neonatologists, that is the maternal and fetal environment and its potential implications for the future health and development of the child (Koletzko, Symonds and Olsen, Am J Clin Nutr 2011;73:671-2).

The programming concept has, over the years, been made broader and also more nuanced. Whereas the original focus was on cardiometabolic diseases and cancer, a number of other diseases and health problems, ranging from bone mineralisation and obesity to mental illnesses, are today also thought to be influenced—programmed — by factors working in the earlier period of life. To indicate that programming may in principal take place during the whole period of development, including infancy and puberty, the broader term developmental programming is more commonly used today; whereas the term early nutrition programming has been coined to designate developmental programming caused specifically by nutritional factors. One of the most promising areas in the whole field is early nutrition programming of atopic diseases.

On page 916 Mozurkewich and colleagues present their systematic review of randomised controlled trials that have studied the impact of perinatal n-3 fatty acid supplementation on atopic diseases. They conclude that supplementation during pregnancy prevents asthma and reduces response to egg skin-prick test in the offspring; whereas their data could not substantiate a corresponding effect of supplementation solely in the lactation period. The authors are fully aware of the two main weaknesses of their analysis, which are the small total number of trials available and their heterogeneity in respect to design and study populations; and which, particularly in combination, create problems for undertaking quantitative syntheses of results. For example, among the five trials included in the review, only one initiated supplementation with n-3 fatty acids during the lactation period; and among the two studies that had examined impact of supplementation during pregnancy on asthma, one had follow up until age 16 whereas the other followed up for 12 months only. However, the paper is important because it gives an excellent overview of the available evidence, which suggests that there is 'something going on' here of potentially great importance. Research is urgently needed on which potential mechanisms could be underlying; Mozurkewich and colleagues mention several possibilities, and more recently proposed anti-inflammatory mechanisms (Oh et al., Cell 2010;142:687-98) and epigenetic mechanisms (Calder et al., Proc Nutr Soc 2010;69:373-80) should also be pursued. The empirical evidence for a possible effect needs to be consolidated (or refuted). Several excellent follow-up studies and trials are well underway and 
we should soon have firm evidence whether increased intake of long-chain n-3 fatty acids in pregnancy can prevent asthma and allergies in the next generation.

\section{Disclosure of interests}

None known (I am lead author on one of the papers [Olsen SF et al. Am J Clin Nutr 2008;88:167-75] that is included in the meta-analysis).

Sjurdur F Olsen

Centre for Fetal Programming, Statens Serum Institut, Copenhagen, Denmark and

Department of Nutrition, Harvard School of Public Health, Boston, USA

Emailsfo@ssi.dk 